\title{
Uncertainty analysis of a decadal simulation with a regional ocean model for the North Sea and Baltic Sea
}

\author{
F. Janssen*, C. Schrum, U. Hübner, J. O. Backhaus \\ Zentrum für Meeres- und Klimaforschung, Universität Hamburg, Troplowitzstr. 7, 22529 Hamburg, Germany
}

\begin{abstract}
A coupled ice/ocean model for the region of the North Sea and the Baltic Sea is presented. It was developed to simulate the inter-annual and intra-annual variability of the dynamic and thermodynamic state of this region. The response of hydrographic conditions to transient forcing was calculated and the ability of the model to describe observed variability of sea surface elevation, temperature and salinity is investigated. Based on various observational data sets, the skill of the model is assessed. It was found that modelled and observed sea surface elevations were highly correlated. The lower frequency variability in sea surface elevation, i.e. periods $>10 \mathrm{~d}$, was described almost perfectly by the model. The bias of the model for sea surface temperature (SST) was about $1^{\circ} \mathrm{C}$ for the summer and about $0.5^{\circ} \mathrm{C}$ for the winter. The inter-annual SST anomalies, including temporal as well as regional variability, are reproduced with greater accuracy. The model was able to realistically describe the development of the halocline in the Baltic Sea. The halocline was preserved over the full cycle of the $15 \mathrm{yr}$ hindcast period. From the results of the present study, it can be concluded that the model is a valuable tool for investigating the regional influence of climate variability and climate change on North Sea and Baltic Sea hydro- and thermodynamics.
\end{abstract}

KEY WORDS: Numerical modelling $\cdot$ Hydrodynamics $\cdot$ Thermodynamics $\cdot$ North Sea $\cdot$ Baltic Sea Climate variability

Resale or republication not permitted without written consent of the publisher

\section{INTRODUCTION}

Many attempts have recently been made to investigate the impact of climate variability and climate change on regional shelf seas (e.g. Tinz 1996, Heyen et al. 1996). Downscaling techniques, based on statistical or dynamical relationships between global and regional parameters, are applied to study the local influence of climate variability. Since it is not known whether a changing climate will cause changes in the statistical relationship between global climate parameters and the local situation, the application of statistical downscaling has some limitations. Regional dynamic models provide an alternative approach, and are particularly useful for investigation of the regional impact of climate change.

*E-mail: janssen@ifm.uni-hamburg.de
Several 3D shelf sea models have been developed for the North Sea/Baltic Sea region in recent years (e.g. Lehmann 1995, Pohlmann 1996, Svendsen et al. 1996, Schrum 1997, Kauker 1998, Meier et al. 1999). The aim of 3 of these models is to simulate the inter-annual variability of the circulation and hydrography. The model of Kauker (1998) was a regional application of the Ocean Isopycnical Model OPYG; Schrum (1997) applied the 'Hamburg Shelf Ocean Model' HAMSOM (for details see Schrum \& Backhaus 1999) and Meier et al. (1999) applied a regional version of the BryanCox-Semtner primitive equation model with a free surface. The focus of the regional OPYG model is the North Sea. It extends towards the North Atlantic and the Baltic Sea, but the horizontal resolution decreases strongly within these regions (e.g. for the Baltic Sea the horizontal resolution is $\sim 40 \mathrm{~km}$ ). Furthermore, due to its isopycnic approach, the vertical resolution of the 
model is low; in wintertime, when the North Sea is vertically well-mixed from surface to bottom, the isopycnic approach results in a $2 \mathrm{D}$ resolution for most of the North Sea area.

A different concept was chosen for the HAMSOM North Sea/Baltic Sea model and for the Baltic Sea model of Meier et al. (1999). The version of HAMSOM presented here was developed as a regional shelf sea model for the North Sea and Baltic Sea, with sufficient horizontal resolution to simulate the inter-annual variability of hydrographic variables in both regions. The same holds true for the vertical resolution: HAMSOM is a z-level model that, in contrast to an isopycnic model, has a constant vertical resolution of a maximum 20 layers during all seasons. The model of Meier et al. (1999) is also a $z$-level model with 40 vertical layers, but it is restricted to the Baltic Sea, with an open boundary in the Kattegat.

First skill assessments for the HAMSOM have already been carried out and these showed that the model is able to describe the main features in the hydrography of North Sea and Baltic Sea. However, detailed validation focusing on inter-annual variability is presented here for the first time. These are necessary before the model can be used for the investigation of the regional influence of climate change.

To investigate whether the model is able to describe the variability of the present climate by using 'perfect' present-day climate forcing is the task of the following contribution. In particular, whether the model is able to describe the variability in sea surface elevation and salinity in the Baltic Sea and SST in the North Sea is investigated.

\section{MODEL DESCRIPTION}

The model is a coupled ice/ocean model with a horizontal resolution of $6 \mathrm{n}$ mile covering the North Sea/ Baltic Sea region (Fig. 1), which results in 8216 wet grid points in the horizontal domain. The vertical dimension is resolved into 20 layers, with a free surface and bottom resolving coordinates. In 3D, the model has 82103 wet grid boxes in total. The model was first presented by Schrum (1997) and is described in detail by Schrum \& Backhaus (1999). Thus, only basic information and differences in comparison to earlier studies will be highlighted.

To calculate hydro- and thermodynamics, the model needs boundary conditions at the atmosphere-ocean interface, for the open boundaries to the North Atlantic and for the river runoff. For the study presented here, the model was forced by monthly fresh water runoff for the region of the North Sea (Damm 1997) and the Baltic Sea (Bergström \& Carlsson 1994). Atmospheric
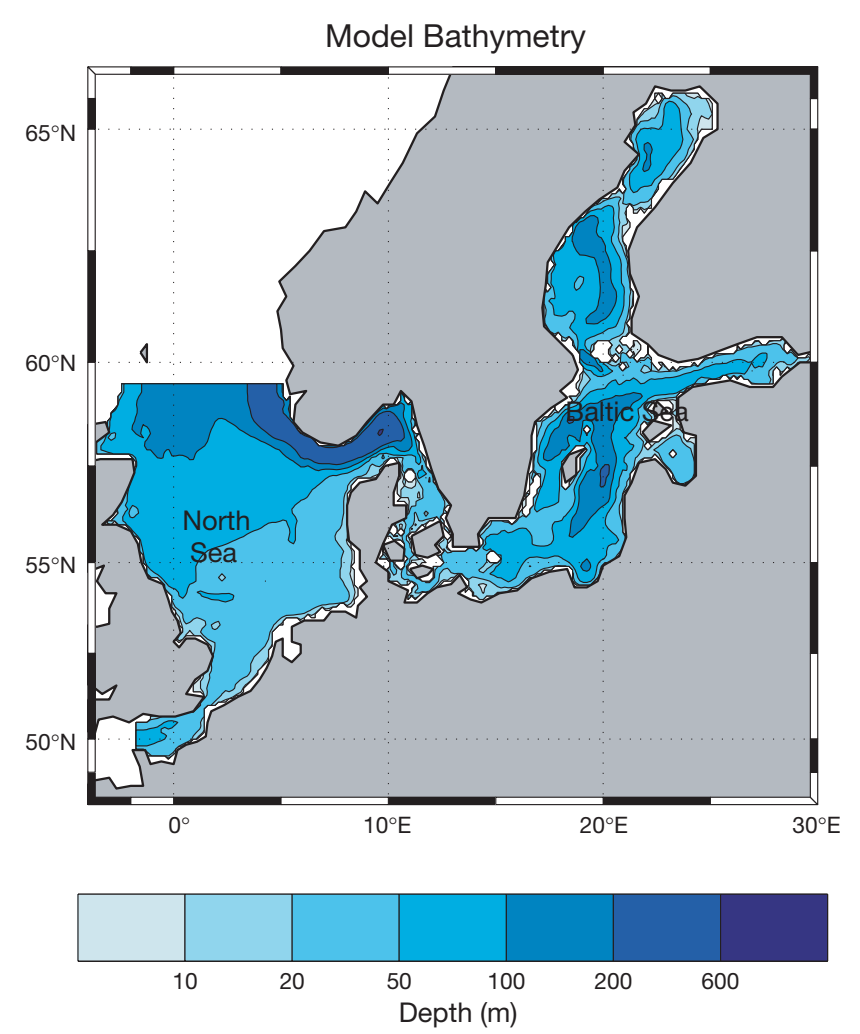

Fig. 1. Model domain and bathymetry

forcing was taken from the ECMWF re-analysis (ERA, Gibson et al. 1996), which is a consistent gridded atmospheric data set with a temporal resolution of $6 \mathrm{~h}$ and a horizontal resolution of T106 $\left(\sim 1.1^{\circ}\right)$. The data set covers the period 1979 to 1993. Mean sea level pressure, $2 \mathrm{~m}$ air temperature, $2 \mathrm{~m}$ dew point temperature and $10 \mathrm{~m}$ winds were taken from the ECMWF reanalysis in order to calculate turbulent fluxes of heat, momentum and fresh water at the atmosphere/ocean and atmosphere/ice interface. The sensible heat flux $Q_{\mathrm{s}}$, latent heat flux $Q_{1}$, evaporation $E$ and windstress $\tau_{\mathrm{a}}$ were calculated by applying the following formulae:

$$
\begin{aligned}
\tau_{\mathrm{a}} & =\rho_{\mathrm{a}} C_{\mathrm{d}} \boldsymbol{V}_{\mathrm{a}}\left|\boldsymbol{V}_{\mathrm{a}}\right| \\
Q_{\mathrm{s}} & =\rho_{\mathrm{a}} C_{\mathrm{HL}} C_{\mathrm{p}}{ }^{\mathrm{a}}\left|\boldsymbol{V}_{\mathrm{a}}\right|\left(T_{\mathrm{a}}-T_{\mathrm{w}}\right) \\
Q_{\mathrm{l}} & =\lambda_{\mathrm{w}} E=\lambda_{\mathrm{w}} \rho_{\mathrm{a}} C_{\mathrm{HL}}\left|\boldsymbol{V}_{\mathrm{a}}\right|\left(q_{\mathrm{a}}-q_{\mathrm{w}}\right)
\end{aligned}
$$

wherein $C_{\mathrm{HL}}$ is the exchange coefficient for sensible and latent heat flux and $C_{\mathrm{d}}$ is the drag coefficient. Both depend on atmospheric stability and on wind speed. They are estimated by using a scheme based on Monin-Obukhov similarity theory (Monin \& Obukhov 1954, Lumley \& Panofsky 1964) presented by Launiainen \& Vihma (1990a). $\rho_{\mathrm{a}}$ is the density of air, $c_{\mathrm{p}}{ }^{\mathrm{a}}$ is the specific heat capacity of air and $\lambda_{\mathrm{w}}$ is the latent heat of water. $T_{\mathrm{w}}$ is the sea surface temperature and $q_{\mathrm{w}}$ is the specific humidity at the sea surface. $\boldsymbol{V}_{\mathrm{a}}$ is the horizon- 
tal wind vector at $10 \mathrm{~m}$ height. $T_{\mathrm{a}}$ is the air temperature and $q_{\mathrm{a}}$ is the specific humidity at $10 \mathrm{~m}$ height. $T_{\mathrm{a}}$ and $q_{\mathrm{a}}$ are calculated from their $2 \mathrm{~m}$ values given in the ERA, as described by Launiainen \& Vihma (1990a). The heat flux contributions due to radiation (short wave solar and longwave thermal) were directly taken from the ERA data, as was the fresh water flux due to precipitation.

At the open boundaries, daily mean sea surface elevations resulting from air pressure, wind and climatological baroclinic forcing are prescribed, calculated by a Northwest European Shelf Sea model (P. Damm, Universität Hamburg, pers. comm. - the transports of this model were investigated by Smith et al. 1996). In addition, sea surface elevation, considering the 3 most important tidal constituents (M2, S2, O1), is prescribed at the open boundaries of the model with a timestep of $20 \mathrm{~min}$. The boundary values for temperature and salinity, as well as their initial conditions, are taken from a climatological monthly mean gridded data set (Janssen et al. 1999). Thus, no inter-annual variability of temperature and salinity of inflowing water was considered for the present runs.

\section{RESULTS AND DISCUSSION}

The uncertainty analysis of the model should answer 2 basic questions: (a) Is the model able to describe regional variability in the Baltic Sea and the North Sea? (b) Is it able to describe the observed temporal variability on intra- and inter-annual timescales? Ideally, these questions should be answered for the main model parameters, i.e. volume transports, sea surface elevation, temperature, salinity and sea ice, and the uncertainty analysis should come up with quantitative estimates of the error for these parameters, which then can be related to the known uncertainties and systematic errors of the observational data sets. This contribution is focused on sea surface elevation, SST and salinity.

\subsection{Sea surface elevation (SSE)}

It is rather difficult to validate simulated transports of an ocean model. Direct measurements of transport in the ocean are only available with very low spatial and temporal resolution, and due to high local variability of transport caused by high variability in wind forcing and local topo- graphy, direct comparison between e.g. a single ADCP time series and a $6 \times 6 \mathrm{n}$ mile mean modelled time series is of questionable utility. Thus, instead of comparing single water transport time series, volume transports are evaluated indirectly. The parameter which served as an indicator for the quality of the estimated volume transports across the open boundaries of North Sea and Baltic Sea is their volume change. Time series of daily Baltic Sea volume, reconstructed from observations of sea surface elevation at tide gauge Degerby, are available for 9 yr, i.e. 1980 to 1988 (Launiainen \& Vihma 1990b). It is well known that sea level change in the centre of the Baltic Sea (e.g. Degerby or Landsort) is representative of volume change, i.e. the mean sea level change of the whole Baltic Sea (e.g. Jacobsen 1980). A new statistical tool was recently developed especially for the task of finding that point in a high dimensional data set which best describes the whole data set (Empirical Orthogonal Teleconnections, EOT; van den Dool et al. 2000). In order to test which model gridpoint best describes the mean sea level variations for the Baltic Sea, we applied this technique to the simulated daily mean SSE of the Baltic, with the results shown in Fig. 2. Fig. 2a shows the regression pattern as a plane sloping from the
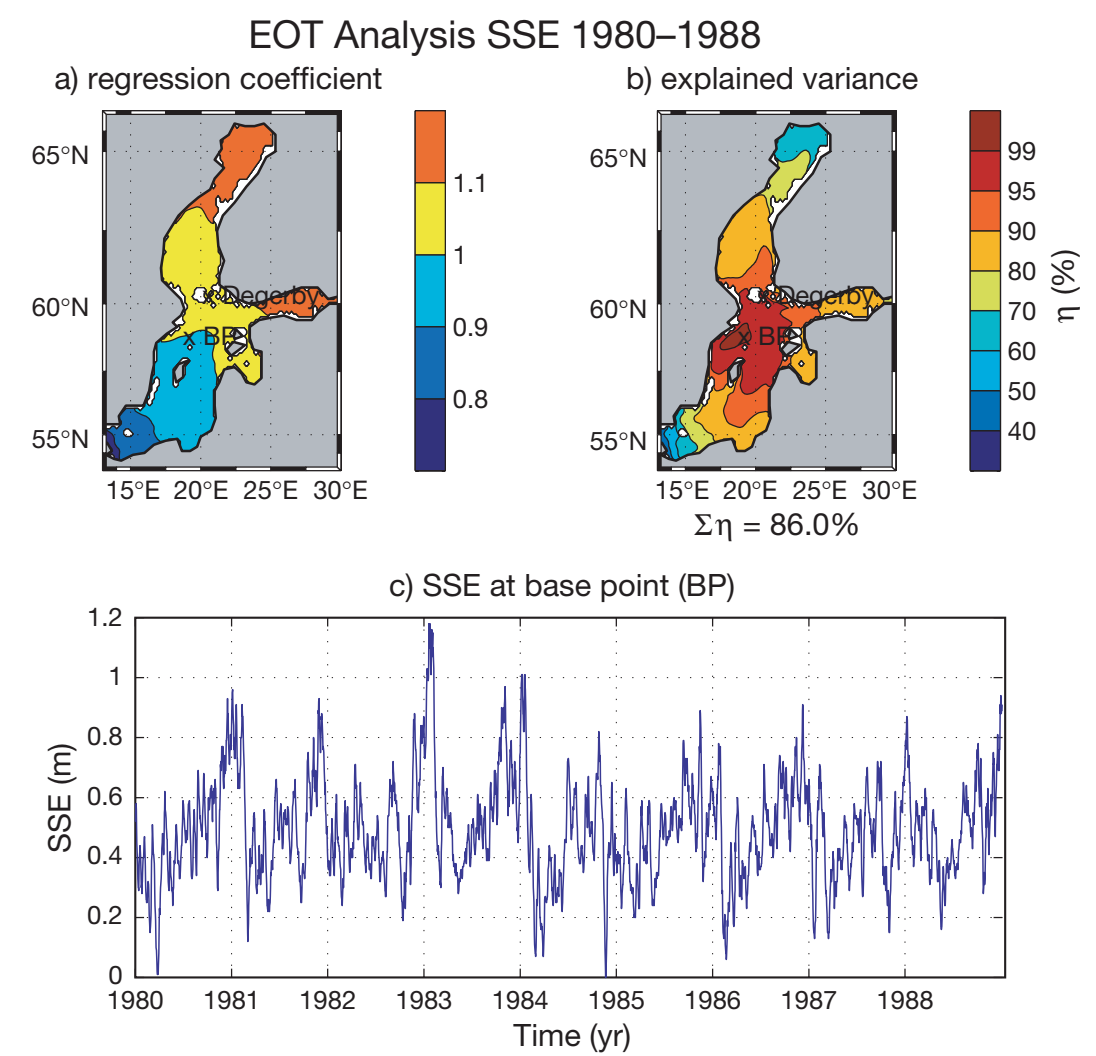

Fig. 2. EOT analysis of simulated daily mean sea surface elevation (SSE) in the Baltic Sea 1980-1988 
southwest to the northeast. The base point (BP) lies somewhat south of Degerby and the corresponding time series is shown in Fig. 2c. As indicated by Fig. 2b, $86 \%$ of the variance in Baltic Sea SSE can be accounted for by this EOT mode. Although the point found to be most representative for the whole Baltic Sea SSE (BP) lies south of Degerby the very high level of variance that can be accounted for at Degerby $(>95 \%)$ indicates that this station also has high skill in describing the variability of Baltic Sea SSE. Thus, it seems to be justified that the data set can be used to investigate the modelled mean Baltic Sea SSE and volume transports.

In Fig. 3a, the modelled volume of the Baltic Sea, as mean sea surface elevation $(\mathrm{m})$, is plotted against observed volume. The scatter plot of observed versus modelled mean sea level shows a very elongated shape with a sharp contour; thus, model results and observa-

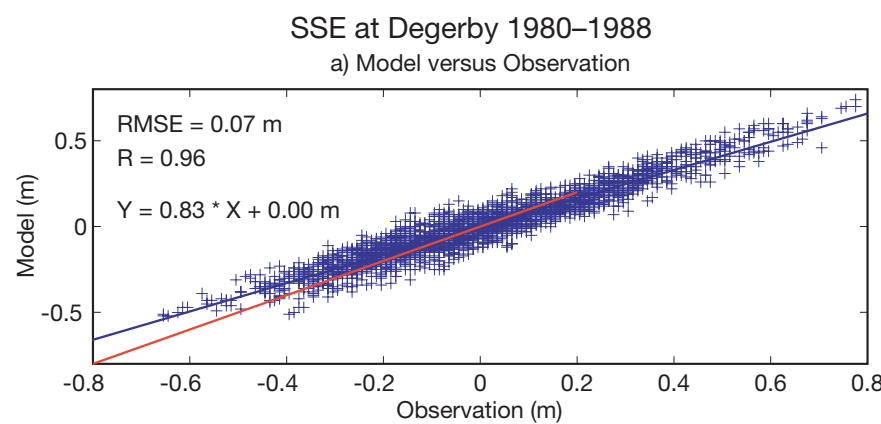

b) 100 days Gaussian low-pass filtered data

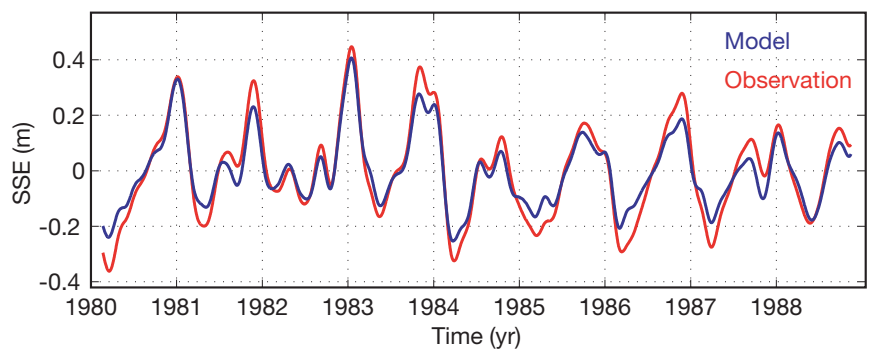

c) Squared coherency

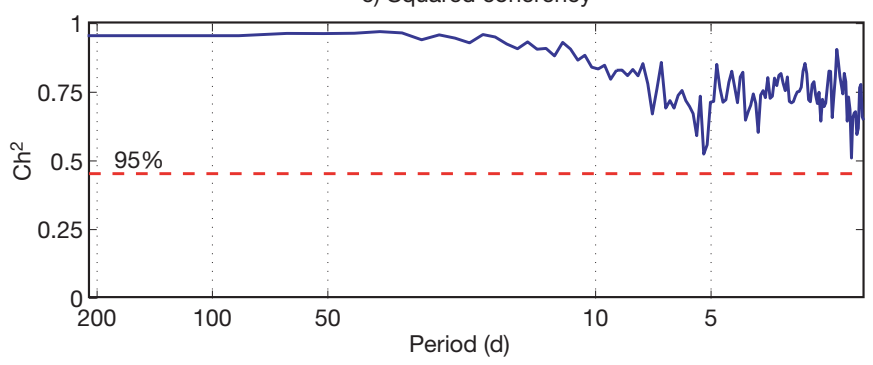

Fig. 3. (a) Scatter plot of observed sea level at Degerby versus simulated mean sea level in the Baltic Sea. Regression, blue line. Optimal regression, red line. (b) Time series of $100 \mathrm{~d}$ lowpass filtered mean SSE. Observations, red line. Simulations, blue line. (c) Squared coherency between simulated and observed mean SSE. Significance level of $95 \%$ indicated by red dashed line tions are highly correlated $(\mathrm{r}=0.96)$. However, more detailed investigation shows an inclination of the linear regression line. The linear relationship between observations $(x)$ and model results $(y)$ is given by the values of $\mathrm{a}=0.83$ and $\mathrm{b}=0.0 \mathrm{~m}$, and points to a systematic underestimation of sea level amplitudes by the model.

The underestimation of amplitudes can also be found in the low-pass filtered time series (Fig. 3b). The $100 \mathrm{~d}$ low-pass filtered time series of model results and observations shows distinct seasonal and inter-annual variability respectively. It is clear from the comparison of both time series that the model slightly underestimates seasonal variability (by $\pm 5 \mathrm{~cm}$ ). The inter-annual variability is reproduced very well by the model. This holds for the variability in the amplitude of the seasonal signal, as well as for the temporal variability of the maximum winter volume.

In Fig. 3c, the squared coherency of the model results and the observations, i.e. the frequency-dependent squared correlation coefficient between model results and observations, is shown. The dashed line in Fig. 3c marks the significance levels of $95 \%$ calculated after the Goodman formula (Panofsky \& Brier 1958).

From the analysis of squared coherency it is obvious that the model is able to reproduce the variability in SSE very realistically over a large frequency range. All values of squared coherency are above the significance limit of $95 \%$, and for timescales $>10 \mathrm{~d}$ the model describes observed variability nearly perfectly. The squared coherency for low frequency variability is $\sim 1$.

\subsection{Sea surface temperature (SST)}

The Bundesamt für Seeschiffahrt und Hydrographie Hamburg (BSH) publishes weekly charts of SST in the North Sea (Becker et al. 1986). These data are available on a $20 \mathrm{n}$ mile grid from 1968 onwards. This data set represents a valuable database for validation purposes due to its high temporal and spatial resolution, and the long period for which it has been processed. In the following this observation-based gridded data set is used to study the skill of the model in reproducing temporal and spatial variability of SST in the North Sea. For the analysis, the modelled data were mapped to the same grid as the SST observations.

In Fig. 4a the bias, i.e. the difference between the mean values, of the weekly mean SST is shown for the $15 \mathrm{yr}$ hindcast period. It can be seen that the model in general overestimates SST during the summer months and underestimates SST during winter. The bias is $\sim 1^{\circ} \mathrm{C}$ for summertime and $0.5^{\circ} \mathrm{C}$ for wintertime. Whether the difference between 2 time series is statistically significant is described by the $t$-test value $t_{\mathrm{SST}}$. The statistical significance test (Fig. 4b) shows that the ob- 


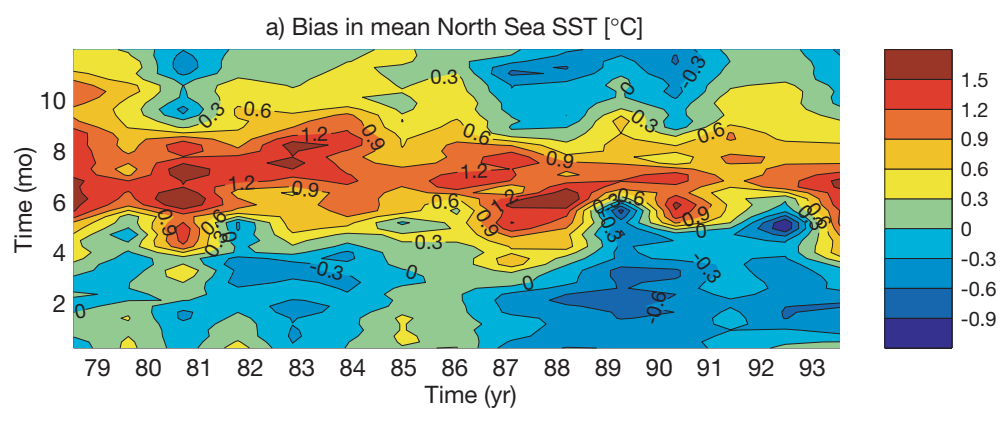

b) Test on significant differences

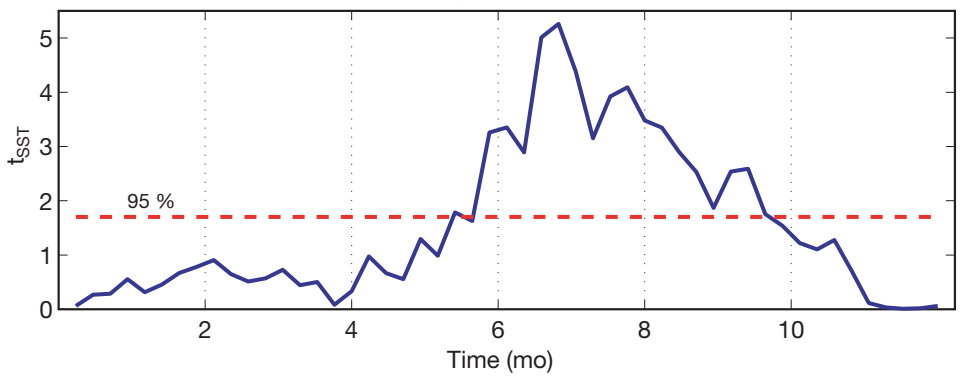

Fig. 4. (a) Temporal development of bias of simulated weekly mean SST in the North Sea, ${ }^{\circ} \mathrm{C}$. (b) Statistical significance test; significance level of $95 \%$ is indicated by red dashed line

served differences between model results and observations are statistically significant only for the summer period, assuming a significance level of $95 \%$. Apparently the discrepancy between observed and simulated SST is the result of a systematic error of the model system (consisting of the ocean model, the boundary conditions and the atmospheric forcing) rather than being caused by stochastic fluctuations. These deviations might be caused by uncertainties in the atmospheric forcing, e.g. by an overestimation of the incoming solar radiation or by uncertainties in the other 3 components of the heat flux. Another possible reason might be that the thickness of the thermocline is underestimated in the model through underestimation of turbulence, which will result in SST being too high.

To investigate whether the model is able to describe the temporal variability of SST, the SST anomalies are calculated both from model results and from observations. Weekly SST anomalies are shown in Fig. 5a. The observed and the modelled SST anomalies are mainly in the range from -2 to +2 degrees. The comparison of the low-pass filtered (1 year Gaussian filter) time series (Fig. 5b), shows that the model reproduces the observed low frequency variability in the SST rather well. To relate observed SST variability to the corresponding physical process, the winter North Atlantic Os- cillation (NAO) index (Hurrell 1996) is given in Fig. 5b. The winter (December to March) NAO index is based on the difference of the normalized sea level pressures between Lisbon, Portugal and Stykkisholmur, Iceland. The anomalies are normalized by the standard deviation of the seasonal pressure (1964-1983). The correlation between winter NAO index and SST has been previously investigated by several authors (e.g. Becker \& Pauly 1996). The advection of air temperature anomalies into the North Sea region is discussed as a possible mechanism to explain a positive correlation between the winter NAO and SST in the North Sea. It would cause a positive winter SST anomaly by decreased cooling due to longwave radiation and sensible heat flux.

The differences between observations and model results for the low-pass filtered time series are mainly in the range of $\pm 0.25^{\circ} \mathrm{C}$, and maximum differences are slightly above $0.5^{\circ} \mathrm{C}$ (e.g. 1981, 1989, 1992). The model underestimates the amplitude of the anomalies. This might be partly caused by a neglect of temperature anomalies in the open boundary conditions. For warm years, temperatures of the inflowing North Atlantic water would be too cold, and for cold years vice versa. Furthermore, neglect of biological influences on the penetration of short wave radiation into the water column might be a source of error. Highly productive years with high turbidity in

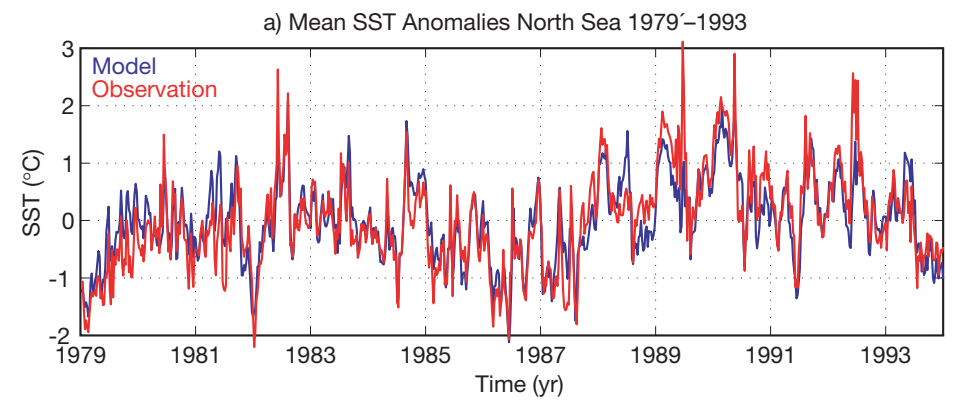

b) 1 year Gaussian low-pass filtered SSTA and NAOWI

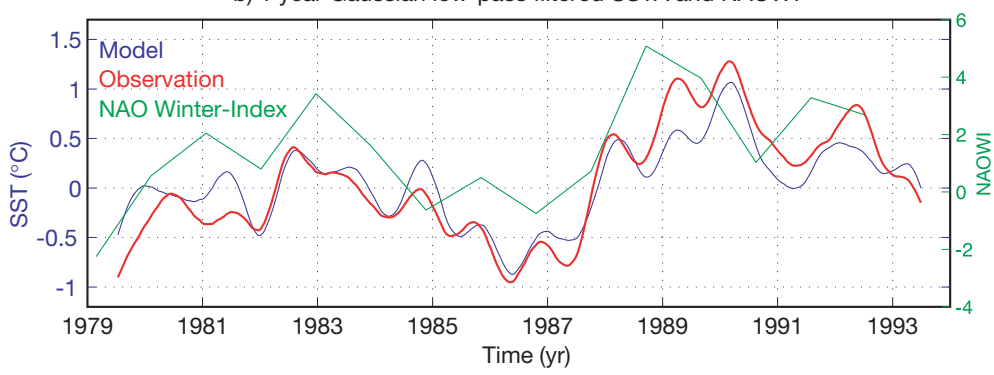

Fig. 5. Time series of (a) weekly mean SST anomalies, (b) 1 yr low-pass filtered weekly SST anomalies. Observations, red line. Simulations, blueline. Units, ${ }^{\circ} \mathrm{C}$. Winter NAO index, green line, dimensionless, calculated after Hurell (1996) 
the water would result in higher absorption of solar radiation near the surface. This would cause a positive SST anomaly. These effects are not considered in the present run and could also be a reason for the underestimation of SST variability. At the beginning of the hindcast (i.e. for the first 2 yr) a phase lag between observations and model results can be found. This is probably caused by the influence of the initial condition for temperature and salinity of the model run, which was a climatological monthly mean for December.

The above analysis focused on temporal variability. No information concerning the ability of the model to reproduce spatial variability could be obtained by these methods. A maximum covariance analysis (MCA) was therefore applied to the gridded observed and modelled SST anomalies (e.g. von Storch \& Zwiers 1999). The MCA yields a set of paired patterns that explain maximum covariance between the 2 variables. In Fig. $6 a-f$, the patterns of the first 3 MCA modes are shown both for observations and model results. These modes account for $67.5 / 73.1 \%, 4.7 / 9.4 \%$ and $4.8 / 6.0 \%$ of the variance in the observed/simulated SST and have linear correlations of $0.86,0.75$ and 0.74 . The first pattern, which reflects the area mean SST anomaly, shows the same basic structure for both observations and model results. The largest differences between patterns (Fig. 6g) can be found in the area of the northern boundary, where the variability in model results is zero due to the climatological boundary condition. The regional amplitude of the first pattern is underestimated in the model compared to the observations. In the western part of the North Sea SST anomalies are overestimated by the model, whereas in the eastern part they are underestimated (Fig. 6h-i). From Fig. $6 g$ it can be concluded that regional variability of SST in the North Sea is underestimated by $\sim 0.2^{\circ} \mathrm{C}$. The fact that regional or seasonal variability of turbidity was not considered may be responsible for the underestimation of the regional variability of SST. This would influence the penetration of short wave radiation into the water

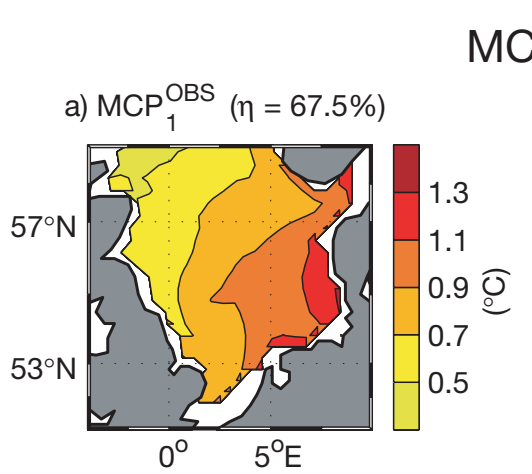

MCA Analysis SSTA 1979-1993

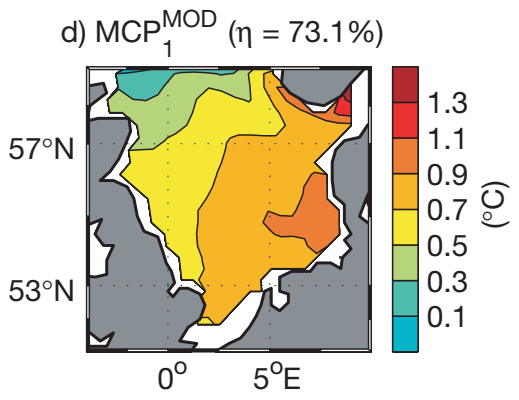

b) $\mathrm{MCP}_{2}^{\mathrm{OBS}}(\eta=4.7 \%)$

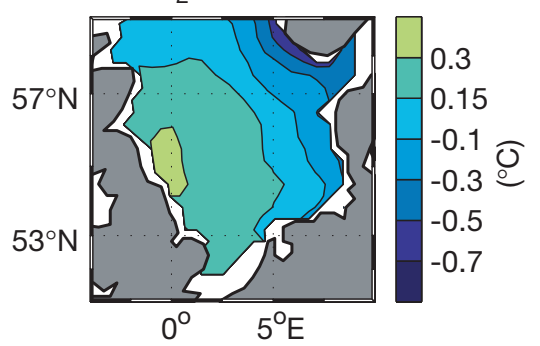

c) $\mathrm{MCP}_{3}^{\mathrm{OBS}}(\eta=4.8 \%)$
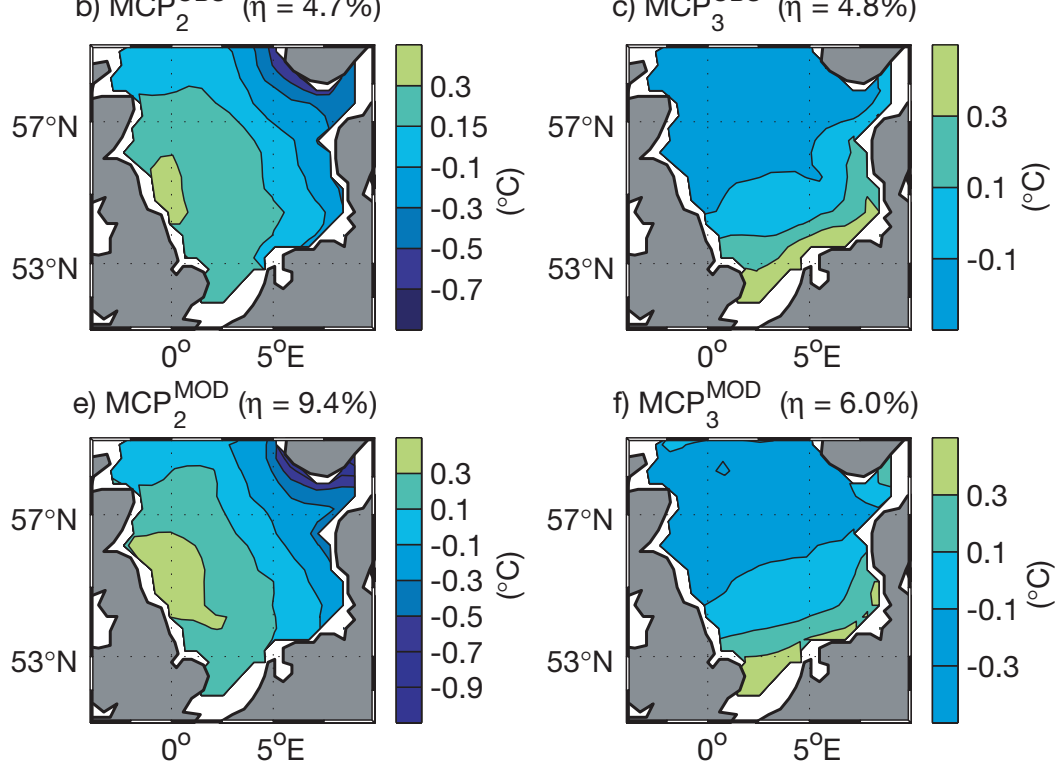

f) $\mathrm{MCP}_{3}^{\mathrm{MOD}}(\eta=6.0 \%)$
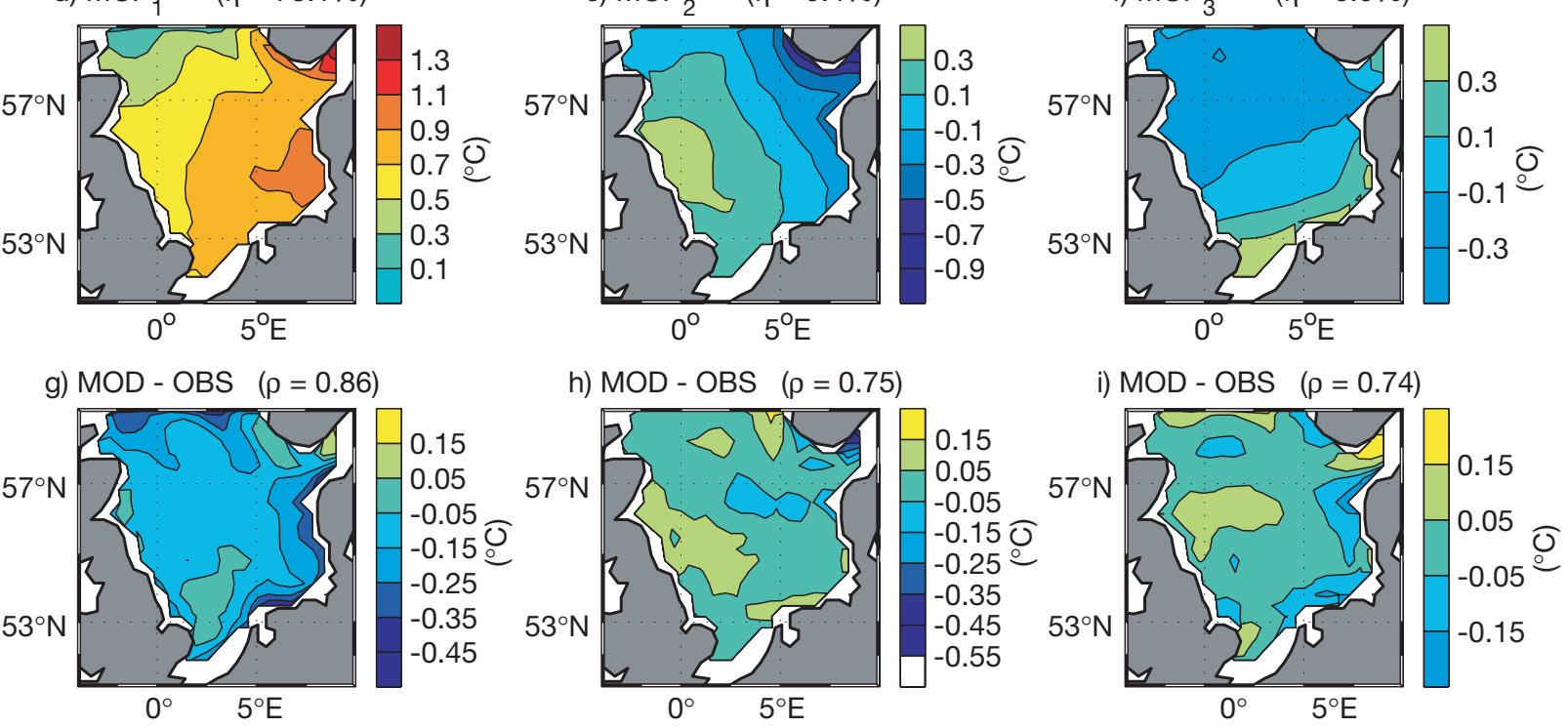

Fig. 6. Maximum covariance patterns (MCP) from analysis of $15 \mathrm{yr}$ of North Sea SST. First 3 patterns from (a-c) observations and $(d-f)$ simulations. $(g-i)$ Differences between observed and simulated MCP. $\eta$, variance accounted for. $\rho$, linear correlation 
column. Another possible cause of the differences in SST might be underestimation of tidal mixing near the British coast and therefore an overestimation of stratification and summer SST. A further potential source of error is the interpolation of atmospheric forcing to the ocean model. Forcing data taken from grid points very close to the shore may be strongly influenced by the terrestrial physics of the atmospheric model and give large differences compared to wet points. Large areas of the ocean model may be affected by this mechanism because of the 'crude' resolution of the atmospheric data $(\sim 100 \mathrm{~km})$ compared to the resolution of the ocean model $(\sim 10 \mathrm{~km})$. Further investigations are needed to decide to what extent the mechanisms mentioned are responsible for the differences in SST. Due to lack of data we cannot give a similar analysis for the SST of the Baltic Sea.

\subsection{Salinity}

Suitable data that can be used to validate the vertical structure of temperature and salinity in the Baltic Sea and North Sea is even more difficult to find than data for surface parameters such as sea level, SST or sea ice. The simulated 3D temperature and salinity distributions show a strong degree of high frequency variability. This could not be derived from the available observed temperature and salinity data due to the problem of undersampling. Even when all available data for almost a century are combined to calculate climatological monthly mean values, there are still large areas in which no data exist (e.g. Janssen et al. 1999). Thus the comparison between model results and observations can be examined only for regions with a large enough number of observations to sufficiently resolve the local natural variability. The area of the Gotland Basin (GB) is 1 of these regions, where, in the framework of the Baltic Sea monitoring programmes, observations are available at a comparatively high temporal resolution $\left(\sim 1 \mathrm{mo}^{-1}\right)$. The GB is located in the Central Baltic Sea. The GB can be considered as an integral measure of the temporal development of salinity in the Kattegat, Belt Sea and the Western Baltic. The exchange rate in the GB is much higher compared to the Gulf of Bothnia or the Gulf of Finland. It can therefore be expected that data from the GB would suffice to describe a large part of the simulated variability, noting that the modelled haline distribution might not be independent of the initial condition during the simulation period of $15 \mathrm{yr}$.

The climatological monthly means (Janssen et al. 1999) were found to be significantly lower ( 1 psu) than actual conditions in the beginning of 1979, which were influenced by a long period of frequent major inflows into the Baltic Sea (Matthäus 1995). Thus the salinity in the initial condition taken from the climatology is significantly underestimated. In Fig. 7 the monthly mean salinity profiles and their respective differences were compared for the full $15 \mathrm{yr}$ hindcast period. It is apparent that the model is able to realistically describe the observed salinity development in the Baltic Sea. The halocline is preserved by the model for the full period and the observed lowering and weakening of the halocline is described in a realistic way. The overall differences are $\sim 1.5 \mathrm{psu}$. Some events however show maximum differences up to $2.1 \mathrm{psu}$ at some depth levels, i.e. at the halocline and in depths $\sim 150 \mathrm{~m}$. From this comparison we conclude that the model realistically describes the vertical structure of the transport field. This also implies that the exchange between the North Sea and Baltic Sea was simulated with some skill. The exchange comprises both the propagation of haline North Sea water into the Baltic Sea and the excess in freshwater run-off from the Baltic Sea. However, we have to point out that the underestimation of salinity due to the initial conditions may have a strong influ-
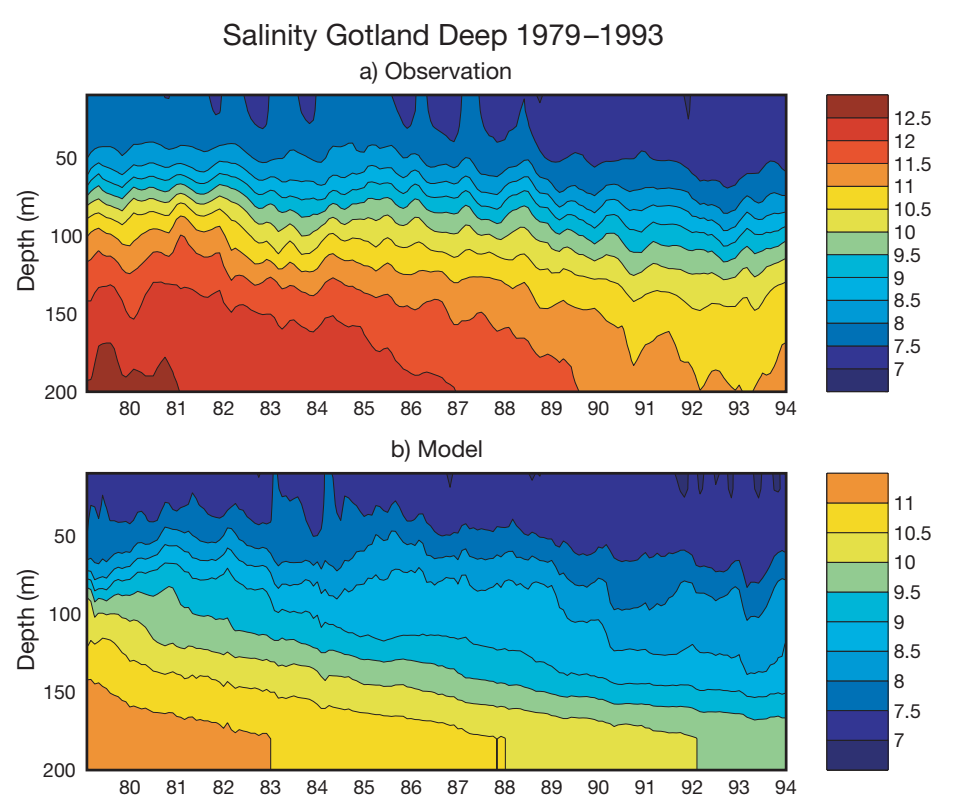

c) Model - Observation

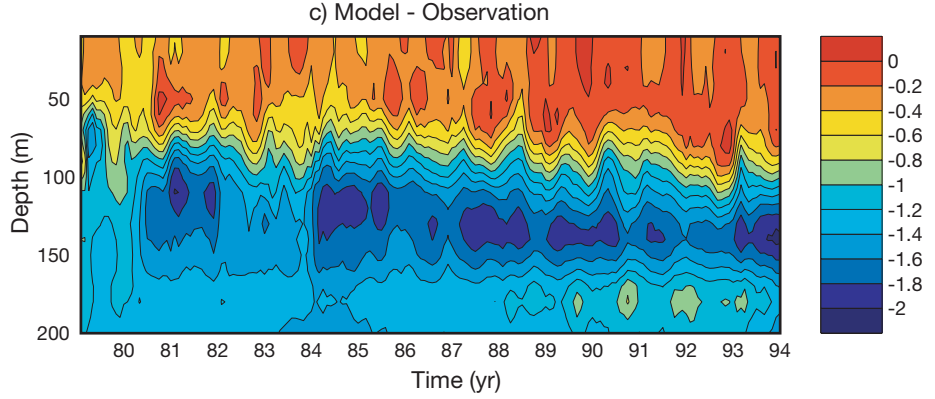

Fig. 7. Monthly salinity profiles in Gotland Sea: (a) observations; (b) simulations; (c) differences between observations and simulations 
ence on the dynamics of the Baltic Sea, e.g. for convection or the spreading of inflowing North Sea water. Model simulations with improved initial conditions should be carried out in order to get an estimate of these processes.

\section{CONCLUSIONS}

The validation examples presented are part of a detailed uncertainty analysis for a model simulation with the regional ocean model HAMSOM using 'perfect' atmospheric boundary conditions. It has been shown that the model is able to simulate regional and temporal (intra-annual and inter-annual) variability of some variables in the North Sea and Baltic Sea, i.e. sea level, temperature and salinity. To show this in detail for several (ideally all) model variables is an important pre-condition before regional forecasts of the impact of global climate variability and climate change can be carried out. Even if the present model results show much room for further improvements, it can be concluded that the model is able to give reliable estimates of natural variability.

Acknowledgements. We are grateful to all our colleagues who contributed to this study by making forcing and validation data available. Freshwater run-off data were provided by S. Bergström, B. Carlsson and P. Damm. Atmospheric forcing data were provided by the European Centre for MediumRange Weather Forecasts (ECMWF) with the kind assistance of the German climate computing centre (DKRZ). J. Launiainen and T. Vihma provided the volume data for the Baltic Sea and G. Becker provided the weekly SST data for the North Sea. We are grateful to the ICES and DOD data centres that made temperature and salinity observations available to us. The study was partly financed by the German Ministry of Education \& Research (BMBF) under grant 03 F01185B, and by the University of Hamburg, Centre for Marine \& Climate Research.

\section{LITERATURE CITED}

Becker GA, Pauly M (1996) Sea surface temperature changes in the North Sea and their causes. ICES J Mar Sci 53: 887-898

Becker GA, Frey H, Wegner G (1986) Atlas der Temperatur an der Oberfläche der Nordsee. Dtsch Hydrogr Z, Ergänzungsheft Reihe B, 17

Bergström S, Carlsson B (1994) River Runoff to the Baltic Sea: 1950-1990. Ambio 23:280-287

Damm P (1997) Die saisonale Salzgehalts- und Frischwasserverteilung in der Nordsee und ihre Bilanzierung. Berichte aus dem Zentrum für Meeres- und Klimaforschung der Universität Hamburg, Germany. Reihe B: Ozeanographie 28

Gibson R, Kallberg P, Uppala S (1996) The ECMWF ReAnalysis (ERA) project. ECMWF Newsletter 73:7-17

Heyen H, Zorita E, von Storch H (1996) Statistical downscaling of winter monthly mean North Atlantic sea-level pressure to sea-level variations in the Baltic Sea. Tellus 48A:312-323
Hurrell JW (1996) Influence of variations in extratropical teleconnections on the Northern Hemisphere temperatures. Geophys Res Lett 23:665-668

Jacobsen TS (1980) The Belt Project — sea water exchange of the Baltic-measurements and methods. The National Agency of Environmental Protection, Denmark

Janssen F, Schrum C, Backhaus J (1999) A climatological data set of temperature and salinity for the North Sea and the Baltic Sea. Dtsch Hydrogr Z, Suppl 9

Kauker F (1998) Regionalization of climate model results for the North Sea. PhD thesis, Universität Hamburg

Launiainen J, Vihma T (1990a) Derivation of turbulent surface fluxes - an iterative flux-profile method allowing arbitrary observing heights. Environ Software 5:113-124

Launiainen J, Vihma T (1990b) Meteorological, ice and water exchange conditions. Second periodic assessment of the state of the marine environment of the Baltic Sea, 1984-1988; background document. Baltic Sea Environ Proc 35B:22-33

Lehmann A (1995) A three-dimensional eddy-resolving model of the Baltic Sea. Tellus 47A:1013-1031

Lumley JL, Panofsky HA (1964) The structure of atmospheric turbulence. Wiley Interscience, New York

Matthäus W (1995) Natural variability and human impacts reflected in long-term changes in the Baltic Deep Water conditions. A brief review. Dtsch Hydrogr Z 47:47-65

Meier M, Döscher R, Coward AC, Nycander J, Döös K (1999) RCO - Rossby Centre regional Ocean climate model: model description (version 1.0) and first results from the hindcast period 1992/93. Rep Oceanogr 26, Swedish Meteorological and Hydrological Institute, Norrköping

Monin AS, Obukhov AM (1954) Dimensionless characteristics of turbulence in the surface layer. Trudy Geofiz Inst Akad Nauk SSSR 24:163-187 (in Russian)

Panofsky HA, Brier GW (1958) Some applications of statistics to meteorology. Pennsylvannia State University, University Park, PA

Pohlmann T (1996) Predicting the thermocline in a circulation model of the North Sea. Part I: model description, calibration and verification. Cont Shelf Res 16:131-146

Schrum C (1997) A coupled ice-ocean model for the North Sea and the Baltic Sea. Sensitivity of North Sea, Baltic Sea and Black Sea to anthropogenic and climatic changes. In: Özsoy E, Mikaelyna A (eds) Sensitivity of North Sea, Baltic Sea and Black Sea to anthropogenic and climatic changes, NATO ASI Series, Environment Vol 27, Kluwer, Amsterdam, p 311-325

Schrum C, Backhaus J (1999) Sensitivity of atmosphere-ocean heat exchange and heat content in the North Sea and the Baltic Sea. Tellus 51A(4):526-549

Smith JA, Damm P, Skogen MD, Flather RA, Pätsch J (1996) An investigation into the variability of circulation and transport on the North-West European Shelf using three hydrodynamic models. Dtsch Hydrogr Z 48:325-348

van den Dool HM, Saha S, Johansson A (2000) Empirical orthogonal teleconnections. J Climate 13:1421-1435

von Storch H, Zwiers FW (1999) Statistical analysis in climate research, Cambridge University Press, Cambridge

Svendsen E, Berntsen J, Skogen M, Adlandsvik B, Martinsen E (1996) Model simulation of the Skagerrak circulation and hydrography during SKAGEX. J Mar Syst 8: $219-236$

Tinz B (1996) On the relation between annual maximum extent of ice cover in the Baltic Sea and sea level pressure as well as air temperature fields. Geophysica 32(3): $319-341$ 